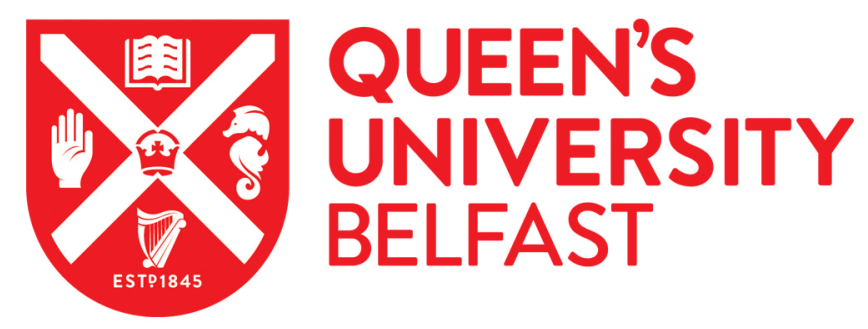

\title{
Enhancing the fracture toughness of hierarchical composites through amino-functionalised carbon nanotube webs
}

\author{
Nistal, A., Falzon, B. G., Hawkins, S. C., Chitwan, R., García-Diego, C., \& Rubio, F. (2019). Enhancing the \\ fracture toughness of hierarchical composites through amino-functionalised carbon nanotube webs. Composites \\ Part B: Engineering, 165, 537-544. https://doi.org/10.1016/j.compositesb.2019.02.001
}

\author{
Published in: \\ Composites Part B: Engineering
}

Document Version:

Peer reviewed version

Queen's University Belfast - Research Portal:

Link to publication record in Queen's University Belfast Research Portal

\section{Publisher rights}

Copyright 2019 the authors.

This is an open access article published under a Creative Commons Attribution-NonCommercial-NoDerivs License

(https://creativecommons.org/licenses/by-nc-nd/4.0/), which permits distribution and reproduction for non-commercial purposes, provided the author and source are cited.

\section{General rights}

Copyright for the publications made accessible via the Queen's University Belfast Research Portal is retained by the author(s) and / or other copyright owners and it is a condition of accessing these publications that users recognise and abide by the legal requirements associated with these rights.

Take down policy

The Research Portal is Queen's institutional repository that provides access to Queen's research output. Every effort has been made to ensure that content in the Research Portal does not infringe any person's rights, or applicable UK laws. If you discover content in the Research Portal that you believe breaches copyright or violates any law, please contact openaccess@qub.ac.uk. 


\section{Enhancing the fracture toughness of hierarchical composites}

\section{through amino functionalised carbon nanotube webs}

Andrés Nistal, ${ }^{a, b *}$ Brian G. Falzon, ${ }^{b * *}$ Stephen C. Hawkins, ${ }^{b, c}$ Ravi Chitwan, ${ }^{b}$ Cristina García-Diego, ${ }^{d}$ and Fausto Rubio, ${ }^{e}$

${ }^{a}$ Institute for Materials Discovery, University College London, Roberts Building WC1E 7JE London, UK.

${ }^{\mathrm{b}}$ Advanced Composites Research Group, School of Mechanical and Aerospace

Engineering, Queen’s University Belfast, Ashby Building, Belfast, BT9 5AH, UK.

${ }^{\mathrm{c}}$ Department of Materials Science and Engineering, Monash University, Clayton, Victoria, 3800, Australia.

${ }^{\mathrm{d}}$ Institute of Catalysis and Petrochemistry (ICP-CSIC). Marie Curie 2, Madrid, 28049, Spain.

${ }^{\text {e }}$ Institute of Ceramics and Glass (ICV-CSIC). Kelsen 5, Madrid, 28049, Spain.

Corresponding Authors:

*E-mail: a.nistal@ucl.ac.uk (A.N.)

** E-mail: b.falzon@qub.ac.uk (B.G.F.) 


\section{ABSTRACT}

The introduction of carbon nanotubes (CNTs) in structural fibre-reinforced polymers, to imbue the composite with multifunctional properties (e.g. enhancing electrical/thermal conductivity, structural health monitoring), has received much attention in recent years. Maintaining, and preferably enhancing, the structural integrity of the composite is imperative. Consequently, strong interfacial bonding between the CNTs and the polymer matrix is sought. If the sought multifunctionality is dependent on specific CNT alignment or orientation, achieved through fragile CNT assemblies, gas-phase chemical functionalisation of the CNT assembly is a viable approach in order to chemically modify the CNT surface without damaging the CNT assembly. This study reports on the gas-phase amino-functionalisation of CNT webs (CNTw) and further explores its influence on the in situ electrical conductivity. The placement of an ethylenediamine-functionalised multilayer CNTw $\left(0.2 \mathrm{~g} \cdot \mathrm{m}^{-2}\right)$ between CF plies resulted in a $13 \%$ enhancement in the interlaminar Mode I fracture toughness, while providing an electrical conductivity of $10^{3} \mathrm{~S} \cdot \mathrm{m}^{-1}$ in the direction of the CNTs within the interleaved CNTw. The effectiveness of the aminofunctionalised CNTw in enhancing the mechanical properties of an epoxy composite is related to an epoxy opening reaction, as demonstrated by Differential Scanning Calorimetry (DSC). Raman and X-ray photoelectron spectroscopies are used to confirm that gas-phase amino-functionalisation does not damage the graphene-based structure and its structural dependent properties.

\section{KEYWORDS}


Carbon Nanotubes, Functional Composites, Surface Treatments, Fracture Toughness, Interface

\section{INTRODUCTION}

Carbon fibre reinforced polymer (CFRP) composite laminates are increasingly being used in aerostuctures [1] because of their superior specific strength and stiffness and excellent fatigue and corrosion resistance. CFRP composite is lightweight when compared to aluminium alloys, but its lower electrical and thermal conductivities necessitate the development of new approaches to anti-icing/de-icing (AI/DI), lightning strike protection (LSP), and, potentially structural health monitoring (SHM) [2, 3]. Moreover, CFRP laminates have poor through-thickness strength and toughness, which make them susceptible to delamination under relative low-energy impact events [4]. To overcome such drawbacks, the addition of carbon nanotubes (CNTs) within the resin, are a promising option, due to their outstanding mechanical, thermal, and electrical properties [5]. Thus, CNTs are considered an ideal candidate to provide multifunctionality to advanced hierarchical CFRP composites [6].

Within a hierarchical composite structure, CNTs can be distributed in the entire matrix, placed around the individual fibres, or distributed between plies [6]. The last option allows to accurately control amount and orientation of the CNTs, what is of paramount importance since different and multiple functionalities can be provided in specific directions and locations, increasing the design options for integrated systems in CFRP multifunctional composites. 
As with any other CNT reinforced nanocomposite, the dispersion of the CNTs and the interfacial interactions between the CNT surface and the matrix are key issues. Dispersion is not a problem where the configuration and orientation of the CNTs are precisely controlled but an appropriate interfacial interaction is needed to ensure that, when CNTs are used for LSP, SHM or AI/DI, an effective load transfer is provided to simultaneously enhance interlaminar fracture toughness [7]. Among the many functionalisation routes for modifying the CNTs to broaden their applications [8], amino-functionalisation is particularly attractive for an epoxy resin (the polymer of choice in CFRP aerospace applications) because the amine can efficiently participate in the cross-linking reaction. Furthermore, amino-functionalisation of dispersed CNTs may further improve the mechanical [9], thermal [7], or electrical [10] performance of a CNT reinforced epoxy nanocomposite.

A number of CNT covalent and non-covalent functionalisation methods have been proposed $[8,11,12]$, which can be divided into two main categories, i.e. wet-chemistry processes and solvent-free gas-phase processes. For CNTs that are accurately oriented in different assemblies, gas-phase processes, that do not affect the CNT morphology, are essential. In addition, solvent-free gas-phase processes are environmentally friendly, reduce the risk of laminate contamination and are scalable. There are three main gas-phase approaches to amino-functionalise graphitic materials: functionalisation through a plasma treatment $[12,13]$, thermochemical functionalisation through thermal activation of the graphitic material and its subsequent reaction with alkenes or halide derivatives via radical addition [14], and thermally activated amination under low pressure [15, 16]. During the 
plasma process, highly energized gas species create activated sites that react with the excited gas (e.g. ammonia) to form functional groups (e.g. amino groups). The main drawback is that it implies certain degradation of the graphene based structure. In contrast, both thermal activation routes are based on functionalisation through existing surface oxide defect sites, mostly carboxylic groups, minimizing the graphene framework degradation and therefore the loss of properties associated with such degradation. This implies a great advantage: the graphitic nanostructure maintains not only its physical distribution and orientation but also its structural integrity. The thermally amination under low pressure route was selected due to its simplicity. Basiuk et al. $[15,16]$ demonstrated that the volatized amines can react with the carboxylic groups present on the CNT surface -either already present as defects or from a pre-treatment- creating amide groups, or simply be physically adsorbed onto the pristine surface of the CNTs.

Previous studies have shown that it is possible to increase the fracture toughness of a CF/Epoxy composite by the addition of CNTs, although results vary widely. Several authors dispersed CNTs in epoxy resin and then prepared a CNT/CF/epoxy composite, which exhibited fracture toughness which was up to $98 \%$ [17-21] higher than the reference baseline. The greatest increases in fracture toughness were mostly observed in low performance epoxies, where, as a specific example, the average critical strain energy release rate in Mode I $\left(G_{I C}\right)$ of such an epoxy, was increased from 86 to $170 \mathrm{~J} \cdot \mathrm{m}^{-2}$ [21]. In contrast, Herceg et al. [20] observed a lower GIC improvement (24\%), for a toughened resin, with the addition of $2.7 \mathrm{vol}$. \% CNTs, reaching a value of $840 \mathrm{~J} \cdot \mathrm{m}^{-2}$. Another approach involved transferring dry vertically aligned CNT forest to the prepregs, observing 
enhancements in $G_{I C}$ ranging from 31 to $150 \%$ [22, 23], or shear-pressing the forest in order to transfer an aligned CNT web or sheet, in which the CNTs were orientated in the plane of the laminate [24], enhancing the Mode I fracture toughness by up to $105 \%$. The latter orientation has been also studied between a glass fibre/epoxy prepreg, and up to a 47 \% enhancement was observed using a CNTw directly wound from a vertically oriented CNT forest [25]. Some authors have functionalised the CNTs through oxidation [24, 34], but the observed improvement in $\mathrm{G}_{\mathrm{IC}}$ was lower than using pristine CNTs. Godara et al. [19] dispersed commercially available amino-functionalised CNTs in the matrix and doubled the improvement obtained with pristine CNTs, demonstrating the potential of this type of functionalisation.

Herein we report for the first time, the gas-phase amino-functionalisation of CNTw to provide multifunctionality to an advanced composite while enhancing the CF/epoxy mechanical properties. As the Achilles' heel of a CFRP composite is the through-thickness strength, the fracture toughness test in Mode I was selected to study the effect of using amino-functionalised CNTw. Highly aligned CNTw directly drawn from CNT forest were treated with a range of diamine types according to a procedure proposed by Basiuk et al. $[15,16]$ and the effect on mechanical and electrical properties measured. In order to study the influence of the amine structure two different aliphatic diamines were employed: one short chain (ethylenediamine, EDA) and one long chain (1,10-diaminodecane, DAD) molecule type. In addition, a tetrafunctional amine (triethylenetetramine, TET) and an aromatic diamine (1,5-diaminonaphtalene, DAN) were also studied.

\section{EXPERIMENTAL PROCEDURE}




\subsection{MATERIALS}

CNT webs were directly drawn from a highly aligned forest, produced by CVD based on a process reported in [26] using a silicon wafer. The nanotubes of the forest obtained are typically about $300 \mu \mathrm{m}$ long and $10 \mathrm{~nm}$ diameter with an average of 6 walls.

Ethylenediamine $\left(\geq 99.5 \%\right.$; bp $\left.=118^{\circ} \mathrm{C}\right), 1,10$-diaminodecane (97\%; vapour pressure of 1.6 KPa at $\left.140{ }^{\circ} \mathrm{C}\right)$, triethylenetetramine $\left(\geq 97.0 \%\right.$; bp $\left.=266-267^{\circ} \mathrm{C}\right)$ and $1,5-$ diaminonaphtalene (97\%; volatile at $200{ }^{\circ} \mathrm{C}$ under vacuum) were used, as received, from Sigma-Aldrich. The high modulus carbon fibre/toughened epoxy resin prepreg (HMC/SE84LV) selected to test the performance of the pristine and amino-functionalised CNT webs was received from Gurit (Gurit Ltd., Isle of Wight, UK). A glass fibre/prepreg RE295/SE84LV used as an insulating equivalent was also provided by Gurit.

\subsection{SAMPLE PREPARATION}

A $60 \mathrm{~mm}$ wide CNTw was drawn directly from the substrate supported-forest and wound onto aluminium frames to a thickness of 10 layers (aerial density of $0.2 \mathrm{~g} \cdot \mathrm{m}^{-2}$ ), as can be seen in Figure S1a. The amine functionalisation was carried out by placing the corresponding amine (5 mg) into a glass receptacle underneath the CNTw $(\sim 0.8 \mathrm{mg})$ in a glass reactor tube within a clamshell furnace (Figure S1b). The system was evacuated to $100 \mathrm{KPa}$ with respect to atmospheric pressure and then heated to $180{ }^{\circ} \mathrm{C}$ at a rate of $\sim 8$ ${ }^{\circ} \mathrm{C} \cdot \mathrm{min}^{-1}$ and held for $2 \mathrm{~h}$ for EDA, DAD, and TET or to $200{ }^{\circ} \mathrm{C}$ for DAN. The reactor was purged with $\mathrm{N}_{2}$ and cooled naturally before opening. The composite double cantilever beam (DCB) specimens were prepared according to the ASTM D5528 [27] standard for Mode I 
fracture toughness testing. To achieve 3-5 mm beam thickness, 12 plies of unidirectional HMC/SE84LV (0.297 mm nominal cured ply thickness) were used, with a $13 \mu \mathrm{m}$ PTFE film inserted between the $6^{\text {th }}$ and the $7^{\text {th }}$ plies to form the pre-crack (Figure S1d). The unidirectional carbon fibres (CFs) are placed in the $\mathrm{x}$ direction and the PTFE film is inserted in the $x-y$ plane. The pristine or amino-functionalised CNTw was placed in the $x-y$ plane, beside the PTFE film (Figure S1c). As can be seen in Figure S1 the orientation of the CNTs in the assembly can be accurately controlled throughout the whole process. The laminates were cured at $120^{\circ} \mathrm{C}$ for $1 \mathrm{~h}$ under constant vacuum, as recommended by the manufacturer.

Since CNTw is intended to be exploited by inserting between the plies of a composite laminate (x-y plane with respect to Figure S1d) to enhance electrical conductivity among other functionalities, we evaluated the influence of amino-functionalisation on the electrical conductivity of CNTw alone. To isolate the CNTw (pristine or amino functionalised), it is placed between two insulating glass fibre composite plies, in direct contact with two copper bus electrodes. The CNTw is in the x-y plane, with the CNTs oriented in the $\mathrm{y}$ direction, perpendicular to the copper buses ( $\mathrm{x}$ direction). The distance between the copper buses is $50 \mathrm{~mm}$ and the width of the CNT web is $60 \mathrm{~mm}$.

\subsection{CNT WEB CHARACTERIZATION}

The CNTw was analyzed by means of Fourier transform infrared spectroscopy in total attenuated reflection mode (FTIR-ATR, Spectrum 100 FT-IR Spectrometer, Perkin-Elmer) 
in the $600-3000 \mathrm{~cm}^{-1}$ range, with a resolution of $4 \mathrm{~cm}^{-1}$ and ten scans, subtracting background for each spectra. Thermogravimetric analysis (TGA, TGA/SDTA851 ${ }^{\mathrm{e}}$, Mettler Toledo) of the CNTw was carried out to $1000{ }^{\circ} \mathrm{C}$ at $10^{\circ} \mathrm{C} \cdot \mathrm{min}^{-1}$ in air. Raman spectra (In Via, Renishaw) of the CNTw were obtained in the $500-3200 \mathrm{~cm}^{-1}$ spectral range using a $514 \mathrm{~nm}$ excitation wavelength and a 50x magnification objective (Leica). Each spectrum was obtained using 10 scans and $10 \mathrm{~s}$ as exposure time. XPS spectra of pristine and EDA treated CNTw were obtained using a PHOIBOS 1509 MCD spectrometer (SPECS GmbH) equipped with a monochromatic $\mathrm{Al} \mathrm{K \alpha} \mathrm{X}$-ray source operating at $200 \mathrm{~W}$ and $12 \mathrm{kV}$ (1486.7 $\mathrm{eV})$. High resolution spectra were obtained with an analyzer pass energy of $25 \mathrm{eV}$, an energy step of $0.1 \mathrm{eV}$ and $100 \mathrm{~ms}$ dwell time per point around the emission lines of interest.

The in situ in-plane electrical conductivity of the CNT webs before and after aminofunctionalisation was calculated from the resistance between the copper bus electrodes ( 5 cm apart with a conductor width of $6 \mathrm{~cm}$ ) (Agilent 34450A 51/2 Digit Multimeter) and the sample thickness. The bus method was developed to address problems presented by the anisotropy and extreme thinness of the CNTw material, and the thin but variable surface resin thickness (and hence resistance) encountered in composites where CNTw is nominally exposed. The morphology of the CNTw was observed by SEM (FlexSEM 1000, Hitachi) at an accelerating voltage of $5 \mathrm{kV}$. The average thickness of the embedded CNTw was obtained by SEM and used to calculate the electrical conductivity of the corresponding CNT/glass fibre/epoxy system. 


\subsection{FRACTURE TOUGHNESS TESTING}

At least five DCB specimens were tested (Instron 5564 Universal Testing Machine) in tensile mode, at a cross head displacement rate of $1 \mathrm{~mm} \cdot \mathrm{min}^{-1}$, tracking the crack length with a microscope-camera. Where multiple cracks were observed to propagate during testing the results were discarded. The fracture surfaces were analyzed using an SEM (FlexSEM 1000, Hitachi) at an accelerating voltage of $5 \mathrm{kV}$. Differential scanning calorimetry (DSC, DSC-6, Perkin-Elmer) were carried out placing the corresponding amine ( $2.5 \mathrm{mg}$ ) between two $4 \mathrm{~mm}$ diameter discs of uncured HMC/SE84LV ( $20 \mathrm{mg})$. The test was run from $30{ }^{\circ} \mathrm{C}$ to $350{ }^{\circ} \mathrm{C}$ at a rate of $10^{\circ} \mathrm{C} \cdot \mathrm{min}^{-1}$.

\section{RESULTS AND DISCUSSION}

\subsection{CNT WEB CHARACTERISATION}

FTIR-ATR analysis indicates (Figure 1) the presence of amino groups in aminefunctionalised CNTw samples. The pristine CNTw spectrum shows only weak bands such as the stretching of the $\mathrm{C}=\mathrm{O}$ carboxyl bond $[28,29]$ or the $\mathrm{C}=\mathrm{C}$ bond adjacent to oxygenated groups at around $1740 \mathrm{~cm}^{-1}$ and $1580 \mathrm{~cm}^{-1}$, respectively [30]. Other weak bands can be observed in the $1350-1450 \mathrm{~cm}^{-1}$ region, where the $\mathrm{CH}_{2}$ and $\mathrm{CH}_{3}$ groups vibrate [31], indicating a small amount of adsorbed hydrocarbon or amorphous carbon. The aminofunctionalisation produced new bands centered at $1070 \mathrm{~cm}^{-1}$ (s), assigned to $\mathrm{C}-\mathrm{N}$ stretching, and at $\sim 1250 \mathrm{~cm}^{-1}(\mathrm{~m})$ and $\sim 1534 \mathrm{~cm}^{-1}$ (w) due to $\mathrm{N}-\mathrm{H}$ bending [29]. The bands due to the amines appear in addition to those from the carboxyl $\mathrm{C}=\mathrm{O}$ and adjacent $\mathrm{C}=\mathrm{C}$ stretching [29] rather than provoking a shift of the $\mathrm{C}=\mathrm{O}$ stretching to $\sim 1620-1650 \mathrm{~cm}^{-1}$, 
where the $\mathrm{C}=\mathrm{O}$ of the amide vibrates $[28,29]$. The absence of this shift to lower wavenumbers indicates that the amino molecules detected by FTIR-ATR are physically adsorbed on the surface of the CNTw rather than covalently bonded. Basiuk et al. $[15,16]$ also observed that the amines were mostly physisorbed on the surface of the CNTs but inferred amide group formation through the detection of two different reaction products by Temperature Programmed Desorption-Mass Spectrometry [15]. From this they estimated the proportion of amide to be one order of magnitude below the physisorbed amine.

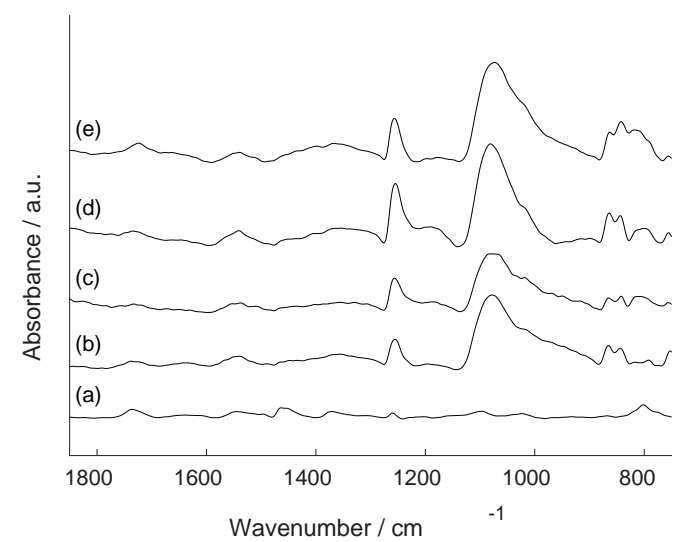

Figure 1. FTIR-ATR spectra of pristine CNTw (a) and amino-functionalised with EDA (b), DAD (c), TET (d) and DAN (e).

Thermogravimetric analysis (TGA) is often used to estimate the extent of CNT functionalisation since the organic moieties incorporated are always decomposed at lower temperature than the stable $\mathrm{sp}^{2}$ carbon of the CNTs graphitic structure. The TGA of pristine CNTw (Figure S2) shows a slight weight loss of 2.9 wt. \% from about $100{ }^{\circ} \mathrm{C}$ to $300{ }^{\circ} \mathrm{C}$, which may be attributed to the loss of adsorbed species such as water, hydrocarbons or amorphous carbon fragments, or the loss of some oxygenated groups, which have already been detected by FTIR-ATR (Figure 1). The CNTw is then stable up to about $550^{\circ} \mathrm{C}$, 
where the degradation of the graphitic structure starts. In contrast, the TGAs of aminofunctionalised CNTw do not exhibit this early weight loss as that material would have been removed by the treatment itself, which entails heating at $\sim 200{ }^{\circ} \mathrm{C}$ under vacuum. (TET does show a small weight loss of about $2 \%$ up to $200{ }^{\circ} \mathrm{C}$ which is attributable to postprocessing moisture adsorption which is well characterised for this amine). Instead they show in all cases two stages of weight loss at temperatures between $200{ }^{\circ} \mathrm{C}$ and $550{ }^{\circ} \mathrm{C}$. The shape of those weight losses is typical of sidewall functionalisation [32], which is consistent with the presence of amine molecules being distributed on the CNT sidewalls.

From the amine TGA curves and first derivatives (Figure S2), the first of the two weight losses (between 200 and $410^{\circ} \mathrm{C}$ ) is ascribed to physisorbed molecules. The second weight loss would usually be attributed to covalently bonded molecules [16, 33-35] however this does not seem to be the case here since it occurs at a temperature too high $\left(410{ }^{\circ} \mathrm{C}\right.$ to 550 ${ }^{\circ} \mathrm{C}$ ) to be considered chemisorbed diamines. Chattopadhyay et al. [36] assigned a weight loss between $150^{\circ} \mathrm{C}$ and $300{ }^{\circ} \mathrm{C}$ to a CNT physisorbed aliphatic amine and Basiuk et al. [16, 33-35] assigned weight losses below $200{ }^{\circ} \mathrm{C}$ to physisorbed amines, while losses between $200{ }^{\circ} \mathrm{C}$ and $360^{\circ} \mathrm{C}$ were attributed to covalently bonded species. Some of those authors functionalised CNT buckypapers with amines in gas-phase [33] and observed also a stepwise TGA curve, with a weight loss between approximately $400{ }^{\circ} \mathrm{C}$ and $600{ }^{\circ} \mathrm{C}$, which was attributed to the CNT surface layer bearing covalently attached amines. Herein it should be highlighted that molecular dynamics simulations have shown that the physical adsorption of amines over a CNT surface takes place preferentially at defect rich areas, interacting with five-membered rings [16] or carboxylic groups [33]. Thus the amount of 
diamine incorporated in each case is calculated from the weight loss between $200{ }^{\circ} \mathrm{C}$ and $410{ }^{\circ} \mathrm{C}$ while weight lost between $410{ }^{\circ} \mathrm{C}$ and $550{ }^{\circ} \mathrm{C}$ is attributed to degradation of the CNT surfaces to which the diamine molecules had been physi- or chemisorbed (Table 1). The fact that, except as noted above, no weight loss is observed below $200{ }^{\circ} \mathrm{C}$ is due to the functionalisation process, in which once the process is completed, the reactor is chilled down to room temperature while purging with a $\mathrm{N}_{2}$ current, so any weakly bonded amines are desorbed and the excess reactant is condensed in the cold areas of the glass reactor, as previously detected by other authors $[15,16]$.

The surface area of the CNTs, which have an average of seven walls and outer diameter of $10 \mathrm{~nm}$, is calculated to be approximately $233 \mathrm{~m}^{2} \cdot \mathrm{g}^{-1}$. The amount of each diamine (wt\%) that could be physisorbed, assuming a molecular monolayer and that the molecules are recumbent rather than standing on-end or on-edge on the CNT surface, is calculated from their respective 2D projections (PubChem open source). The actual amounts of amine adsorbed are calculated from the TGA loss up to $410{ }^{\circ} \mathrm{C}$ and expressed as a \% of the theoretical maximum (Table 1) equivalent amine monolayer (EAM). Thus EDA is adsorbed to the extent of around $4.30 \mathrm{wt} \%\left(1.43 \mathrm{meq} \cdot \mathrm{g}^{-1}\right)$ or $32 \%$ of the maximum theoretical amount (which would be $13.4 \%$ $\left(4.47 \mathrm{meq} \cdot \mathrm{g}^{-1}\right)$.

The high temperature $\left(410^{\circ} \mathrm{C}-550^{\circ} \mathrm{C}\right)$ weight loss observed with the TGAs is interpreted as indicating the amount of CNT surface that had been in contact with the adsorbed amines. If this interpretation is qualitatively valid, an approximation of the area previously covered by amine can be estimated (Table 1), using the areal mass of single layer graphene (ie the outer CNT shell) of $2600 \mathrm{~m}^{2} \cdot \mathrm{g}^{-1}$. From this, it is estimated for example that only around 
$15 \%$ of the CNT surface was covered with EDA, suggesting that the adsorbed molecules may have been oriented on-end or as a bi-layer rather than as a recumbent monolayer. A similar mismatch is seen between the calculated EAM value and the CNT surface cover for the other alkyl amines (DAD, TET), whereas the aromatic compound DAN is closer with 23\% EAM and 18\% CNT coverage. Although these are at best approximations, this suggests that the DAN predominantly lies flat on the CNT surface as might be expected due to aromatic $\pi-\pi$ interactions whose importance has already been demonstrated [33].

$\mathrm{t}$

Table 1. Amount of incorporated amine (wt. \%), the corresponding $\mathrm{NH}_{2}$ equivalent weight, the theoretical percentage of CNT surface covered by an equivalent amine monolayer (EAM), the amount of CNT in contact with the diamine (wt. \%) and the corresponding CNT surface (\%)

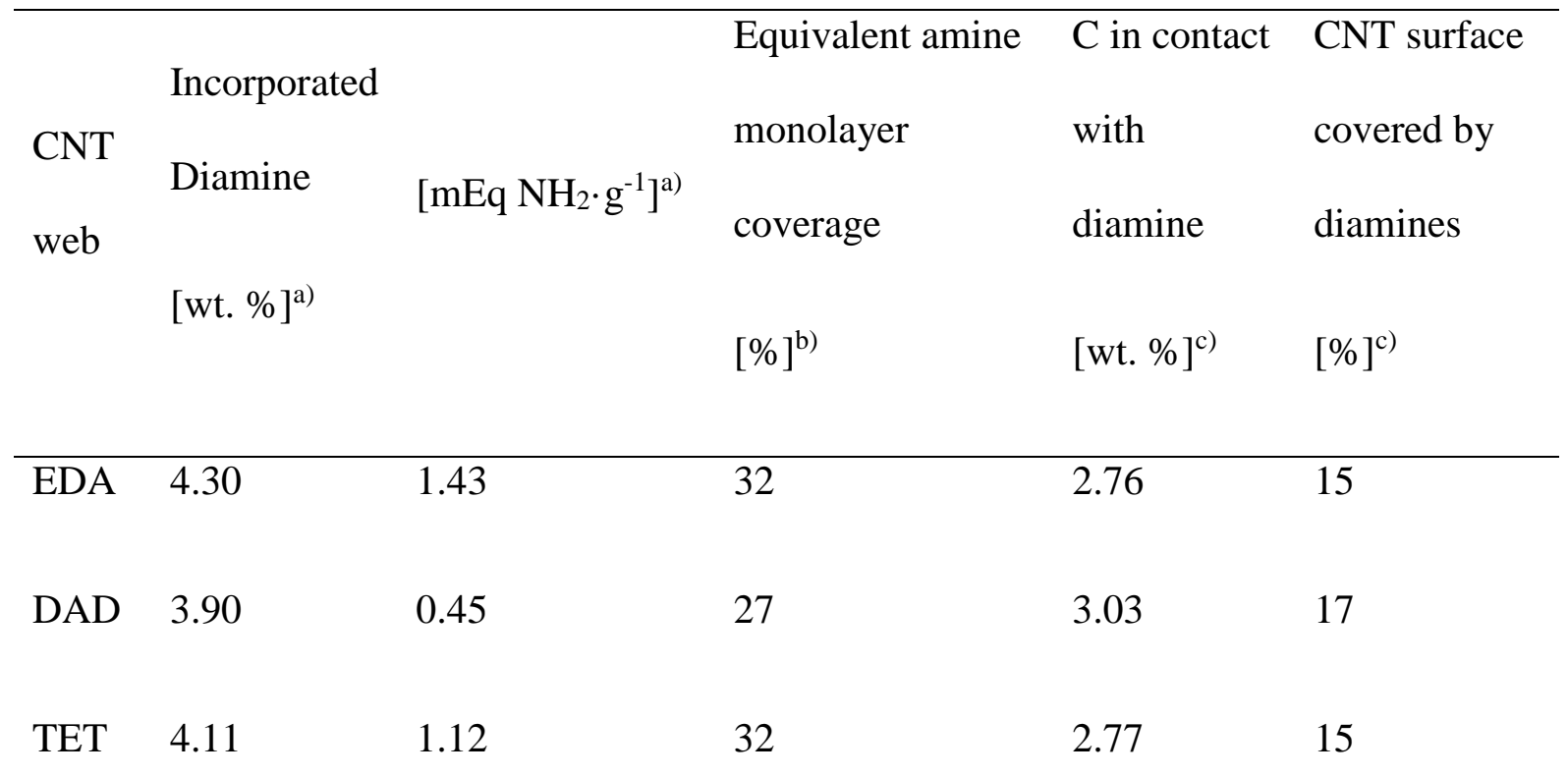


a) Calculated from the weight loss observed between $200{ }^{\circ} \mathrm{C}$ and $410{ }^{\circ} \mathrm{C}$; b) Calculated assuming a parallel orientation of the amines over the average CNT surface of the present work; ${ }^{c)}$ Calculated from the weight loss observed between $410{ }^{\circ} \mathrm{C}$ and $550{ }^{\circ} \mathrm{C}$. Further detail is available in Supporting Information.

Raman spectroscopy and SEM was performed on the untreated pristine CNTw and also on the EDA treated one (Figure S3). In both spectra, the main characteristic peaks of graphene based structures can be seen, i.e. D, G and 2D bands [38]. Centered at $\sim 1350 \mathrm{~cm}^{-1}$ is the D band, which is due to the breathing modes of the $\mathrm{sp}^{2}$ rings. At a Raman shift of $\sim 1580 \mathrm{~cm}^{-1}$ the $\mathrm{G}$ band can be seen, associated with the vibration of the defect-free $\mathrm{sp}^{2}$ carbons of the graphene-like structure. Commonly, the relation between the integrated intensities of D and G bands $\left(I_{D} / I_{G}\right)$ is used to quantify the extent of disorder. Finally, at $\sim 2700 \mathrm{~cm}^{-1}$ the $2 \mathrm{D}$ band is clearly observed in both spectra, which is related to the layered order. The pristine CNTw and the amino treated CNTw show the same $I_{D} / I_{G}$ value of 0.49 . As expected, the low temperature activated amination does not degrade the graphitic structure of the CNTw.

The SEM images show that the CNTs are highly oriented within the webs, both before and after the amino-functionalisation (Fig. S4b). This demonstrates that the gas-phase treatment has not affected the orientation of the CNTs. Both Raman spectroscopy and electron microscopy have demonstrated the suitability of the thermally activated amination process in order to modify a CNT assembly without disturbing its structural integrity or physical distribution and orientation. 
Pristine and EDA CNTw were further characterized by X-ray photoelectron spectroscopy (XPS). Carbon, oxygen and impurities of organic silicon were detected on both samples. However, although XPS is a very surface sensitive technique, nitrogen was not observed in any sample (see Figure S3). This may be explained by suggesting that the physisorbed EDA molecules are desorbed under the ultra-high vacuum (UHV) used in XPS. Taking into account that the amines are incorporated in the $4 \mathrm{wt}$. \% range (Table 1), the maximum
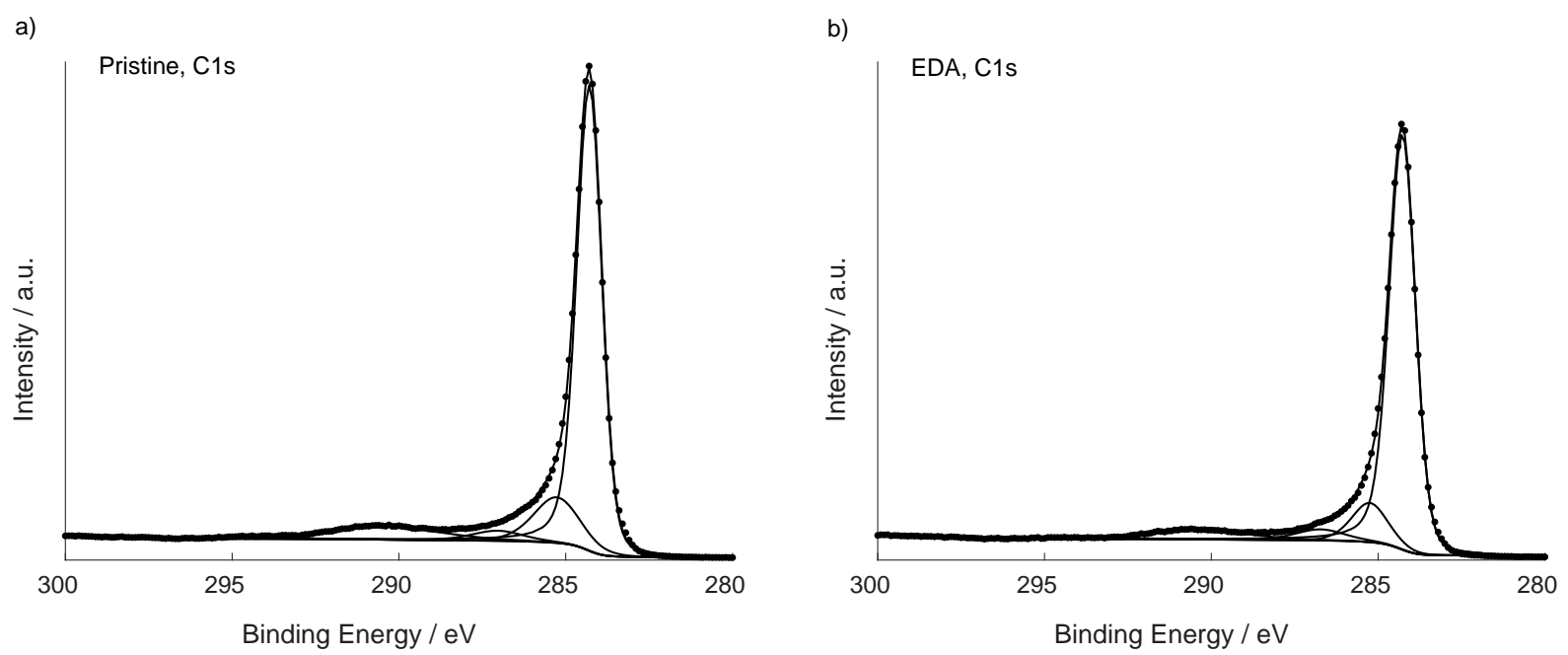

amount of nitrogen incorporated is about $2 \mathrm{wt}$. \% only (calculated for EDA, the studied amine with the highest nitrogen proportion). If only $10 \%$ of the incorporated amine is chemisorbed, as previously observed by other authors [15], the amount of nitrogen due to amine chemisorption would be 0.2 wt. \%. Taking into account the high purity of the CNTs employed herein (low amount of carboxylic groups are expected) this covalent incorporation could be even lower that the one already observed by Basiuk et al. [15], which would fall below the detection limit of FTIR and XPS techniques.

Figure 2. C 1s peak-fitting of pristine (a) and EDA (b) treated CNTw. 
High resolution spectra of C1s are shown in Figure 2, where a main asymmetrical peak at $284.3 \mathrm{eV}$, which represents the $\mathrm{sp}^{2}$ hybridized carbon atoms of the nanotube structure, can be observed. The peak centered at $285.3 \mathrm{eV}$ can be assigned to $\mathrm{sp}^{3}$ carbon atoms. Also, $\mathrm{C}=\mathrm{O}$ was observed (287.0 eV for pristine $\mathrm{CNTw}$ and $286.7 \mathrm{eV}$ for EDA CNTw), whose presence was confirmed in the O1s spectra, where oxygen doubly bound to carbon at 531.7 - $531.9 \mathrm{eV}$ was observed. Additionally, the characteristic shake-up $\pi \rightarrow \pi^{*}$ lines of carbon in aromatic compounds were observed above $290 \mathrm{eV}$. Since EDA molecules were mainly adsorbed and thus desorbed under the UHV of the XPS, the material that is under analysis is in both cases that of the CNT only, either pristine or after amine adsorption-desorption process. Here it worth noting that no significant changes were observed in terms of oxygenated groups. The most prominent difference after the amino-functionalisation treatment is the elimination of some $\mathrm{sp}^{3}$ carbon species, as already observed by FTIR (Figure 1).

\subsection{MODE I FRACTURE TOUGHNESS}

In order to study the effect on fracture toughness of the nano-modified CFRP laminates, Mode I double cantilever beam (DCB) specimens, of unidirectional carbon fibre (CF), were prepared with the corresponding CNTw at $90^{\circ}$ with respect to the CF orientation (Table 2). The average strain energy release rate $\left(G_{I C}\right)$, during propagation of the crack in Mode I, was calculated (Table 2) using the Modified Compliance Calibration Method in accordance with the ASTM D5528 standard [27]. Using the analysis of variance test (ANOVA) a pvalue of 0.0009 was obtained, indicating that the results are statistically significant. If pristine CNTw are used as an interleave between the CF/epoxy plies, a 9\% depreciation in 
interlaminar fracture toughness is observed. This emphasizes the need of surface modification to enhance the load transfer at the CNT/epoxy interface, in order to ensure that the structural integrity of the laminate is, at least, not compromised, if their introduction is motivated by the need to provide non-structural functionality such as increased thermal and/or electrical conductivity. If the CNTw is treated with EDA, a $13 \%$ improvement in $G_{I C}$ with respect to the non-reinforced CFRP system is observed, while the improvement is up to $24 \%$ if compared with the use of pristine CNTw. On the other hand, if the CNTw is treated with the long aliphatic-chain counterpart (DAD), a higher depreciation is observed. The functionalisation with the tetramine (TET) shows a $10 \%$ improvement while the use of the aromatic diamine (DAN) has almost no effect on the Mode I behavior if compared with the pristine CNTw, showing a similar decrease in the average strain energy release rate.

Table 2. GIC obtained from Mode I fracture toughness test of DCB specimens with pristine and functionalised CNTw at the crack interface.

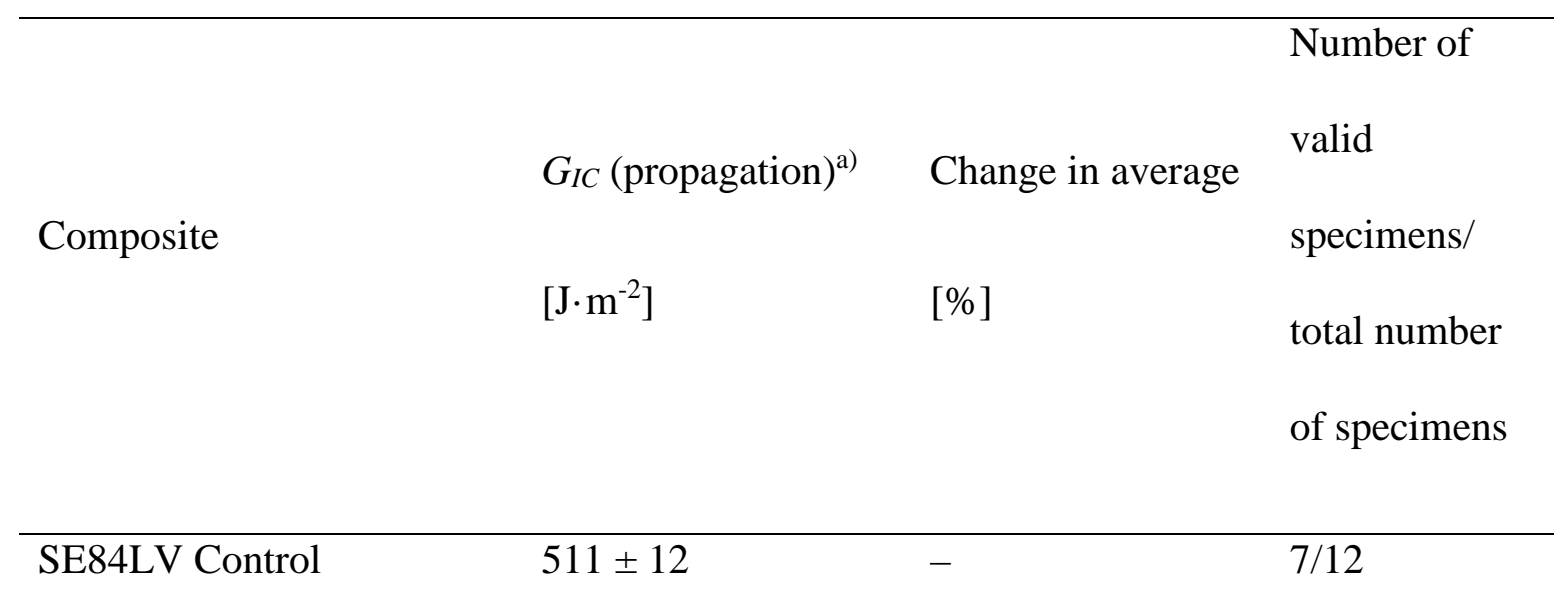




$\begin{array}{lccc}\text { SE84LV / Pristine CNTw } & 467 \pm 36 & -9 \% & 9 / 18 \\ \text { SE84LV / EDA-CNTw } & 580 \pm 47 & +13 \% & 8 / 9 \\ \text { SE84LV / DAD-CNTw } & 428 \pm 124 & -16 \% & 4 / 5 \\ \text { SE84LV / TET-CNTw } & 562 \pm 51 & +10 \% & 3 / 6 \\ & & & \\ \text { SE84LV / DAN-CNTw } & 450 \pm 74 & -12 \% & 8 / 9\end{array}$

a) $\mathrm{p}$-value $=0.0009$.

There is a correlation between the mode I fracture toughness (Table 2) and the extent of $\mathrm{NH}_{2}$ groups incorporated in each case (Table 1). In the case of the functionalisation with EDA, $1.43 \mathrm{mEq} \mathrm{NH} \cdot \mathrm{g}^{-1}$ are incorporated and a $13 \%$ improvement in GIC $_{I C}$ is observed. For the TET-functionalised CNTw, a 10\% improvement is observed, with an incorporation of $1.12 \mathrm{mEq} \mathrm{NH} \cdot \mathrm{g}^{-1}$. These correspond to $24 \%$ and $20 \%$ improvements respectively if compared with the incorporation of pristine CNTw. In contrast, DAN and DAD CNTw show $12 \%$ and $16 \%$ reduction in $G_{I C}$ respectively but very low $\mathrm{NH}_{2}$ incorporations $(0.41$ and $0.45 \mathrm{mEq} \mathrm{NH} \cdot \mathrm{g}^{-1}$ respectively, Table 1$)$.

\subsection{DIFFERENTIAL SCANNING CALORIMETRY}

Differential scanning calorimetry (DSC) of the CF/SE84LV epoxy prepreg shows (Figure 3) a single exothermic peak starting at about $120{ }^{\circ} \mathrm{C}$ (the curing temperature recommended by the manufacturer) that is unambiguously assigned to the cross-linking reaction of the epoxy resin. This same peak can be seen for every amine-treated prepreg sample (Figure 3). The three aliphatic amines EDA, TET and DAD also exhibit an exotherm which starts at 
about $40^{\circ} \mathrm{C}, 44{ }^{\circ} \mathrm{C}$ and $60{ }^{\circ} \mathrm{C}$, respectively, whereas no such exotherm is shown by the aromatic DAN. These exotherms are attributable to the reactions between the respective aliphatic amine and the epoxide moiety which occur at temperatures well below the recommended curing temperature. The temperature required to activate the aromatic amine DAN is above the curing temperature of the epoxy system such that by the time this temperature is reached, there is no epoxide left to react with and hence no exotherm. Failure of the DAN to effectively cross-link with the epoxide would account for the lack of improvement and indeed slight reduction compared with pristine CNT as it would perhaps hinder access to the CNT surface.

In contrast to DAN, DAD clearly reacts with the epoxide but causes even more depreciation in performance. Compared with EDA, DAD causes a $26 \%$ reduction and $8 \%$ below the CNTw alone indicating a strong negative effect of aliphatic chain length. The comparison between the theoretical EAM for DAD (27 \%) and the experimentally observed CNT surface covered by DAD (17 \%) (Table 1) suggest certain deviation from a parallel orientation. Thus, it could be due to a non-effective DAD molecule orientation, presenting the oily chain to the epoxide matrix.

The DSC plot of DAD also exhibits (Figure 3) a sharp endothermic peak centered at about $65^{\circ} \mathrm{C}$ which is attributable to the melting of DAD (melting point of ca. $67^{\circ} \mathrm{C}-69^{\circ} \mathrm{C}$ ). Both EDA and TET are liquids at room temperature while DAN melts at about $185^{\circ} \mathrm{C}-$ $187^{\circ} \mathrm{C}$ by which temperature it is very likely to have already dissolved in the epoxy resin. 
From these results it is evident that the interfacial interactions between the CNTw and the epoxy matrix has a paramount effect on the interlaminar fracture toughness of the composite, but there are other parameters to take into account, such as the aromaticity of the diamine or the chain length. Those parameters may affect the temperature at which the diamine reacts with the epoxy system and also the preferential orientation of the diamines with respect the CNT surface.

Finally, a slightly lower GIC improvement is observed with the polyamine functionalisation (TET-functionalised CNTw) if compared with the diamine functionalisation with similar amino incorporation (EDA-functionalised CNTw). This could be explained taking into account that in TET there are four amino groups per molecule, while in EDA there are only two, and thus a better distribution of the amino groups over the CNT surface can be expected in the latter.

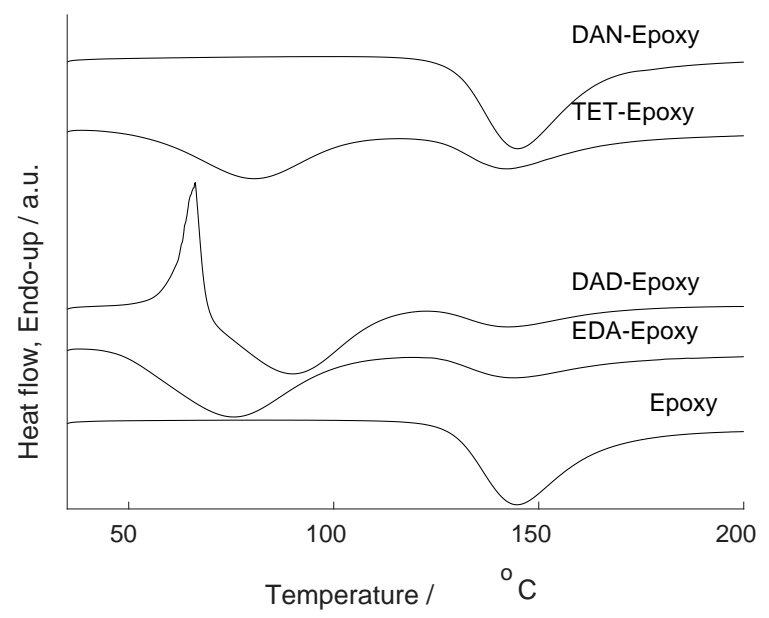

Figure 3. DSC of the pristine CF/Epoxy system and with EDA, DAD, TET and DAN.

\subsection{FRACTOGRAPHY}


The fractography analysis of the fresh fracture surfaces following Mode I testing (Figure 4) supports the hypothesis that the improvement in $G_{I C}$, observed in the composite reinforced with EDA-treated CNTw, is due to the reaction between the amine and the epoxy matrix. In all cases, loose carbon fibres are observed at low magnification (Fig 4, a-d, left), as a result of fibre bridging. Also, at higher magnification there is evidence to suggest a more torturous route of the crack path through the CNTw (Fig 4, b-d, center). In addition to this, when the CNTw are treated with EDA it can be observed that some epoxy resin fragments are attached around the CNTs. This debris is due to the early reaction between the EDA and the epoxy rings of the resin that takes place at certain points around the CNTs, as demonstrated by DSC (Figure 3). To a lesser extent, the debris can also be seen on the fracture surface of the DAD-CNT and TET-CNT composites (Figure S6). This is probably related to the higher temperature required to activate those aliphatic amines and could also be due to a different orientation of those amines with respect to the CNT surface. Indeed, no debris was observed around the CNTs on the fracture surface of the DAN-CNT composite.

Even though a covalent amino-functionalisation could produce a stronger CNT-matrix interface that might transfer the load to the reinforcing phase more efficiently, noncovalent amino-functionalisation of CNTs has already been proved effective [39-40]. 

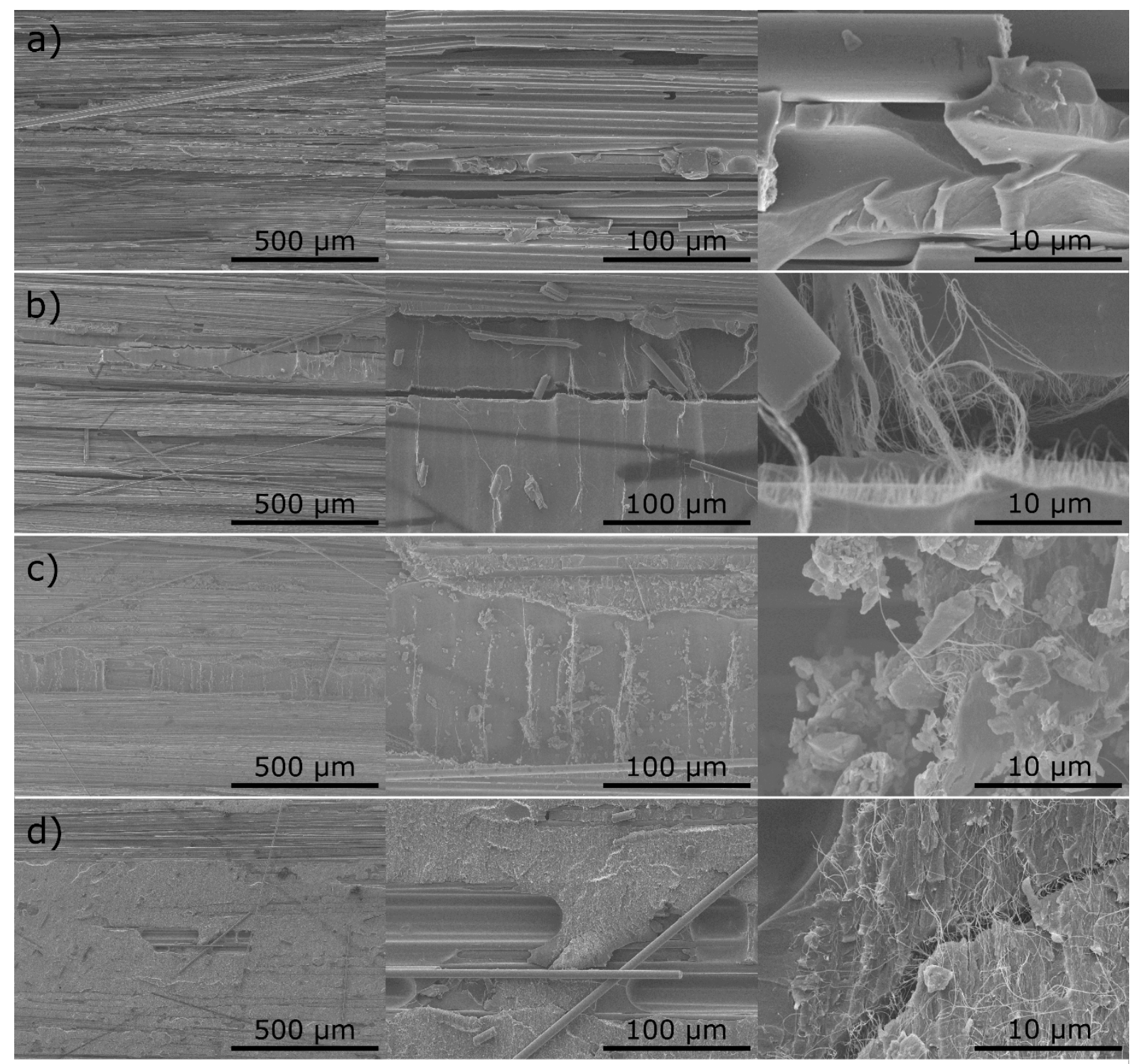

Figure 4. SEM images of the fracture surface of CF/SE84LV (a), reinforced with pristine CNTw (b), EDA treated CNTw (c) or DAN treated CNTw. DAD and TET treated CNTw images are available in the supplementary information.

\subsection{ELECTRICAL CONDUCTIVITY}

The electrical conductivity of the CNTw was measured, both after and before the aminofunctionalisation with EDA. Using the two probe method, an electrical resistance of $74.2 \Omega$ 
and $89.3 \Omega$ was measured for pristine and EDA treated CNTw respectively. Assuming an average thickness of $6 \mu \mathrm{m}$ and considering the area of the webs, an electrical conductivity of $1.9410^{3} \mathrm{~S} \cdot \mathrm{m}^{-1}$ and $1.5610^{3} \mathrm{~S} \cdot \mathrm{m}^{-1}$ was calculated for pristine and EDA treated CNTw respectively. The slight decrease in electrical conductivity observed after EDA functionalisation is attributable to the high affinity of the diamine for the CNT surface which amounts to a solvation or surfactant effect (which in other reports contributes to dispersion). Under the conditions of our experiment, EDA molecules are anticipated to infiltrate the junctions between the CNTs and thereby slightly increase the contact resistance. Nevertheless, the observed electrical resistance is potentially high enough for several applications, from electromagnetic shielding, where just $10^{1} \mathrm{~S} \cdot \mathrm{m}^{-1}$ or better is required [41], to de-icing, where CNT based systems with in-plane conductivities from $142 \mathrm{~S} \cdot \mathrm{m}^{-1}[42]$ to $6.4910^{3} \mathrm{~S} \cdot \mathrm{m}^{-1}[43]$ have proven effective.

Chu et al. [43] observed an electrical conductivity of $7.7810^{3} \mathrm{~S} \cdot \mathrm{m}^{-1}$ by introducing only 1.45 wt. \% of CNTs but in the form of a paper, with a thickness of ca. $70 \mu \mathrm{m}$. Herein, the in-plane electrical conductivity is in the same order of magnitude but the thickness of the CNTw introduced is about $6 \mu \mathrm{m}$, one order of magnitude lower than the CNT paper used by Chu et al., [43] with a weight increment of $\sim 0.2 \mathrm{~g} \cdot \mathrm{m}^{-2}$. Indeed, Falzon's research group $[44,45]$ have recently demonstrated the suitability of using CNTw embedded in a composite laminate to develop a highly tuneable electro-thermal system for AI/DI applications using the same CNTw employed herein. Thus, the electrical conductivity that the CNT web presents even after functionalisation demonstrates the CNTs maintain their structural integrity. 


\section{CONCLUSIONS}

The non-covalent amino-functionalisation (physisorption) of CNTw in gas-phase reaction has been shown to be an effective method to increase the chemical interactions between the CNT surface and the epoxy matrix. This enhancement yielded a 13\% improvement in fracture toughness when the CNTw were functionalised with ethylenediamine, and a 24\% improvement if compared with the pristine CNTw. This work has further shown that the suitability of an organic amine to enhance the fracture toughness of a CNT/CF/epoxy laminate depends, among other parameters, on the temperature required to activate the organic amine towards the epoxy ring opening reaction, which can be measured by differential scanning calorimetry (DSC). Raman, XPS, and SEM confirmed that the thermally activated functionalisation process did not affect the CNT structural integrity, nor its physical distribution or orientation. In addition, the electrical conductivity was maintained in the region of $10^{3} \mathrm{~S} \cdot \mathrm{m}^{-1}$ even after functionalisation, making it suitable for several applications including electromagnetic shielding or de-icing. This opens the possibility of using amino-functionalised CNTw to provide directional multifunctionality to a CF/epoxy laminate with a negligible increase in weight of only $0.2 \mathrm{~g} \cdot \mathrm{m}^{-2}$, while also toughening the material.

\section{Supporting Information}

CNTw (10 layers) supported on an aluminium frame; CNTw gas-phase amino functionalisation reactor; CNTw placed at $90^{\circ}$ with respect of the CF during the preparation of the composite preparation of DCB specimen for Mode I fracture toughness testing 
(Figure S1). TGA and first derivative of pristine and amino functionalised CNTw (Figure S2). Raman spectroscopy and SEM images of pristine and EDA treated CNTw (Figure S3). XPS survey of pristine and EDA-functionalised CNTw (Figure S4). N1s peak region of EDA treated CNTw (Figure S5). SEM images of the fracture surface of CF/SE84LV reinforced with DAD treated CNTw and TET treated CNTw (Figure S6)

\section{ACKNOWLEDGMENTS}

This work was supported by the UK Engineering and Physical Sciences Research Council (EPRSC) grant EP/N007190/1.

\section{REFERENCES}

[1] McConnell VP. Past is prologue for composite repair. Reinf Plast 2011; 55(6): 17-21.

[2] Gohardani O, Elola MC, Elizetxea C. Potential and prospective implementation of carbon nanotubes on next generation aircraft and space vehicles: a review of current and expected applications in aerospace sciences. Prog Aerosp Sci 70 (2014) 42-68.

[3] Thostenson ET, Chou TW. Carbon nanotube networks: sensing of distributed strain and damage for life prediction and self healing. Adv Mater 2006; 18: 2837-2841.

[4] Tan W, Falzon BG, Chiu LNS, Price M. Predicting low velocity impact damage and compression-after-impact (CAI) behaviour of composite laminates. Compos A: Appl Sci Manuf 2015; 71: 212-226.

[5] Dresselhaus MS, Dresselhaus G, Eklund PC. Science of fullerenes and carbon nanotubes. Academic Press, 1996. 
[6] Qian H, Greenhalgh ES, Shaffer MSP, Bismarck A. Carbon nanotube-based hierarchical composites: a review. J Mater Chem 2010; 20(23) 4751-4762.

[7] Khare KS, Khabaz F, Khare R. Effect of carbon nanotube functionalisation on mechanical and thermal properties of cross-linked epoxy-carbon nanotube nanocomposites : role of strengthening the interfacial interactions. ACS Appl Mater Interfaces 2014; 6(9): 6098-6110.

[8] Tasis D, Tagmatarchis N, Bianco A, Prato M. Chemistry of carbon nanotubes. Chem Rev 2006; 106(3): 1105-1136.

[9] Gojny FH, Wichmann MHG, Fiedler B, Schulte K. Influence of different carbon nanotubes on the mechanical properties of epoxy matrix composites - a comparative study. Comp Sci Technol 2005; 659(15-16): 2300-2313.

[10] Zhang A, Luan J, Zheng Y, Sun L, Tang M. Effect of percolation on the electrical conductivity of amino molecules non-covalently coated multi-walled carbon nanotubes/epoxy composites. Appl Surf Sci 2012; 258(21): 8492-8497.

[11] Ma PC, Siddiqui NA, Marom G, Kim JK. Dispersion and functionalisation of carbon nanotubes for polymer-based nanocomposites: a review. Compos Part A: Appl Sci Manuf 2010; 41(10): 1345-1367.

[12] Alam A, Wan C, McNally T. Surface amination of carbon nanoparticles for modification of epoxy resins: plasma-treatment vs. wet-chemistry approach. Eur Polym J 2017; 87: 422-448. 
[13] Khodadadei F, Ghourchian H, Soltanieh M, Hosseinalipour M, Mortazavi Y. Rapid and clean amine functionalisation of carbon nanotubes in a dielectric barrier discharge reactor for biosensor development. Electrochim Acta 2014; 115: 378-385.

[14] Menzel R, Tran MQ, Menner A, Kay CWM, Bismarck A, Shaffer MSP. A versatile, solvent-free methodology for the functionalisation of carbon nanotubes. Chem Sci 2010; 1(5): 603-608.

[15] Basiuk EV, Basiuk VA, Bañuelos JG, Saniger-Blesa JM, Pokrovskiy VA, Gromovoy TY, Mischanchuk AV, Mischanchuk BG. Interaction of oxidized single-walled carbon nanotubes with vaporous aliphatic amines. J Phys Chem B 2002; 106(7): 1588-1597.

[16] Basiuk EV, Monroy-Peláez M, Puente-Lee I, Basiuk VA. Direct solvent-free amination of closed-cap carbon nanotubes: a link to fullerene chemistry. Nano Lett 2004; 4(5): 863-866.

[17] Karapappas P, Vavouliotis A, Tsotra P, Kostopoulos V, Paipetis A. Enhanced fracture properties of carbon reinforced composites by the addition of multi-wall carbon nanotubes. J Compos Mater 2009; 43(9): 977-985.

[18] Romhány G, Szebényi G. Interlaminar crack propagation in MWCNT/fiber reinforced hybrid composites. Express Polym Lett 2009; 3(3): 145-151.

[19] Godara A, Mezzo L, Luizi F, Warrier A, Lomov SV, Van Vuure AW, Gorbatikh L, Moldenaers P, Verpoest I. Influence of carbon nanotube reinforcement on the processing 
and the mechanical behaviour of carbon fiber/epoxy composites. Carbon 2009; 47(12): 2914-2923.

[20] Herceg TM, Abidin MSZ, Greenhalgh ES, Shaffer MSP, Bismarck A. Thermosetting hierarchical composites with high carbon nanotube loadings: en route to high performance. Compos Sci Technol 2016; 127: 134-141.

[21] Yokozeki T, Iwahori Y, Ishiwata S, Enomoto K. Mechanical properties of CFRP laminates manufactured from unidirectional prepregs using CSCNT-dispersed epoxy. Compos Part A: Appl Sci Manuf 2007; 38(10): 2121-2130.

[22] Falzon BG, Hawkins SC, Huynh CP, Radjef R, Brown C. An investigation of mode I and mode II fracture toughness enhancement using aligned carbon nanotubes forests at the crack interface. Compos Struct 2013; 106: 65-73.

[23] Garcia EJ, Wardle BL, Hart AJ. Joining prepreg composite interfaces with aligned carbon nanotubes. Compos Part A: Appl Sci Manuf 2008; 39(6): 1065-1070.

[24] Stahl JJ, Bogdanovich AE, Bradford PD. Carbon nanotube shear-pressed sheet interleaves for mode I interlaminar fracture toughness enhancement. Compos Part A: Appl Sci Manuf 2016; 80: 127-137.

[25] Bhanushali H, Bradford PD. Woven glass fiber composites with aligned carbon nanotube sheet interlayers. J Nanomater 2016; Article ID 9705257.

[26] Huynh CP, Hawkins SC. Understanding the synthesis of directly spinnable carbon nanotube forests. Carbon 2010; 48 (4): 1105-1115. 
[27] Standard test method for mode I interlaminar fracture toughness of unidirectional fiber-reinforced polymer matrix composites. ASTM International: West Conshohocken, PA, 2007.

[28] Zhu J, Peng H, Rodriguez-Macias F, Margrave JL, Khabashesku VN, Imam AM, Lozano K, Barrera EV. Reinforcing epoxy polymer composites through covalent integration of functionalised nanotubes. Adv Funct Mater 2004; 14(7): 643-648.

[29] Li L, Wang J, Wenbo L, Wang R, Yang F, Hao L, Zheng T, Jiao W, Jiang L.

Remarkable improvement in interfacial shear strength of carbon fiber/epoxy composite by large-scare sizing with epoxy sizing agent containing amine-treated MWCNTs. Polym Compos 2016, DOI: 10.1002/pc.24263

[30] Mawhinney DB, Naumenko V, Kuznetsova A, Yates JT, Liu J, Smalley RE. Infrared Spectral evidence for the etching of carbon nanotubes: ozone oxidation at 298 K. J Am Chem Soc 2000; 122(10): 2383-2384.

[31] Okolo GN, Neomagus HWJP, Everson RC, Roberts MJ, Bunt JR, Sakurovs R, Mathews JP. Chemical-structural properties of south african bituminous coals: insights from wide angle XRD-carbon fraction analysis, ATR-FTIR, solid state 13C NMR, and HRTEM techniques. Fuel 2015; 158: 779-792.

[32] Zhao Y, Barrera EV. Asymmmetric diamino functionalisation of nanotubes assisted by BOC protection and their epoxy nanocomposites. Adv Funct Mater 2010; 20: 3039-3044. 
[33] Basiuk EV, Ramírez-Calera IJ, Meza-Laguna V, Abarca-Morales E, Pérez-Rey LA, Re M, Prete P, Lovergine N, Álvarez-Zauco E, Basiuk VA. Solvent-free functionalisation of carbon nanotube buckypaper with amines. Appl Surf Sci 2015; 357: 1355-1368.

[34] Basiuk EV, Ochoa-Olmos O, Contreras-Torres FF, Meza-Laguna V, Alvarez-Zauco E, Puente-Lee I, Basiuk VA. “Green” functionalisation of pristine multi-walled carbon nanotubes with long-chain aliphatic amines. J Nanosci Nanotechnol 2011; 11(6): 55465554.

[35] Basiuk EV, Basiuk VA, Meza-Laguna V, Contreras-Torres FF, Martínez M, RojasAguilar A, Salerno M, Zavala G, Falqui A, Brescia R. Solvent-free covalent functionalisation of multi-walled carbon nanotubes and nanodiamond with diamines: looking for cross-linking effects. Appl Surf Sci 2012; 259: 465-476.

[36] Chattopadhyay D, Galeska I, Papadimitrakopoulos F. A route for bulk separation of semiconducting from metallic single-wall carbon nanotubes. J Am Chem Soc 2003; 125(11): 3370-3375.

[37] Bonaccorso F, Colombo L, Yu G, Stoller M, Tozzini V, Ferrari AC, Ruoff RS, Pellegrini V. Graphene, related two-dimensional crystals, and hybrid systems for energy conversion and storage. Science 2015; 347(6217), 1246501.

[38] Ferrari AC, Meyer JC, Scardaci V, Casiraghi C, Lazzeri M, Mauri F, Piscanec S, Jiang D, Novoselov KS, Roth S, Geim AK. Raman spectrum of graphene and graphene layers. Phys Rev Lett 2006; 97, 187401. 
[39] Cha J, Jun GH, Park JK, Kim JC, Ryu HJ, Hong SH. Improvement of modulus, strength and fracture toughness of CNT/epoxy nanocomposites through the functionalisation of carbon nanotubes. Compos Part B: Eng 2017; 129: 169-179.

[40] Qi Z, Tam Y, Wang H. Xu T, Wang L, Xiao C. Effects of noncovalently

functionalised multiwalled carbon nanotube with hyperbranched polyesters on mechanical properties of epoxy composites. Polym Testing 2017; 64: 38-47.

[41] Li N, Huang Y, Du F, He X, Lin X, Gao H, Ma Y, Li F, Chen Y, Eklund PC.

Electromagnetic interference (EMI) shielding of single-walled carbon nanotube epoxy composites. Nano Lett 2006; 6(6): 1141-1145.

[42] Yamamoto N, Guzman de Villoria R, Wardle BL. Electrical and thermal property enhancement of fiber-reinforced polymer laminate composites through controlled implementation of multi-walled carbon nanotubes. Compos Sci Technol 2012; 72(16): 2009-2015.

[43] Chu H, Zhang Z, Liu Y, Leng J. Self-heating fiber reinforced polymer composite using meso/macropore carbon nanotube paper and its application in deicing. Carbon 2014; 66: 154-163.

[44] Yao X, Falzon BG, Hawkins SC, Tsantzalis S. Aligned carbon nanotube webs embedded in a composite laminate: a route towards a highly tunable electro-thermal system. Carbon 2018; 129: 486-494. 
[45] Yao X, Hawkins SC, Falzon BG. An advanced anti-icing/de-icing system utilizing highly aligned carbon nanotube webs. Carbon 2018; 136: 130-138. 


\section{Supporting Information}

\section{Enhancing the fracture toughness of hierarchical composites through amino functionalised carbon nanotube webs}

Andrés Nistal, ${ }^{a, b *}$ Brian G. Falzon ${ }^{b * *}$, Stephen C. Hawkins, ${ }^{b, c}$ Ravi Chitwan, ${ }^{b}$ Cristina García-Diego, ${ }^{d}$ and Fausto Rubio, ${ }^{e}$

${ }^{\text {a }}$ Institute for Materials Discovery, University College London, Roberts Building WC1E 7JE London, UK.

b Advanced Composites Research Group, School of Mechanical and Aerospace Engineering, Queen’s University Belfast, Ashby Building, Belfast, BT9 5AH, UK.

c Department of Materials Science and Engineering, Monash University, Clayton, Victoria, 3800, Australia.

${ }^{\mathrm{d}}$ Institute of Catalysis and Petrochemistry (ICP-CSIC). Marie Curie 2, Madrid, 28049, Spain.

e Institute of Ceramics and Glass (ICV-CSIC). Kelsen 5, Madrid, 28049, Spain.

\section{Corresponding Authors}

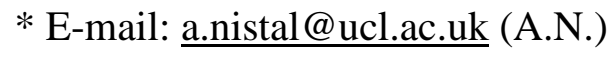

** E-mail: b.falzon@qub.ac.uk (B.G.F.) 


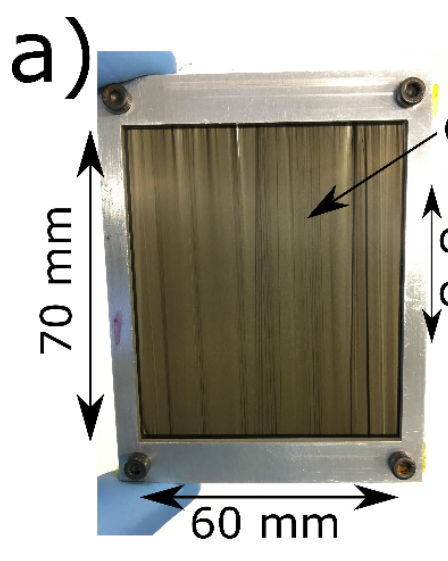

c)

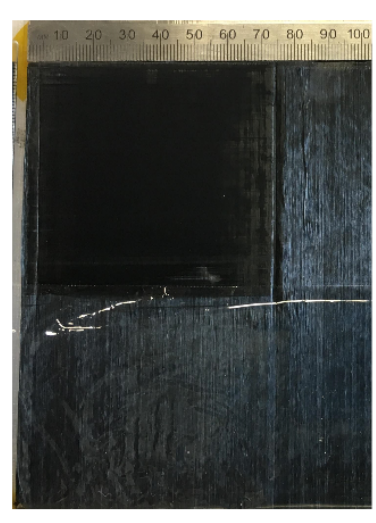

CNT web

$A$

draw direction
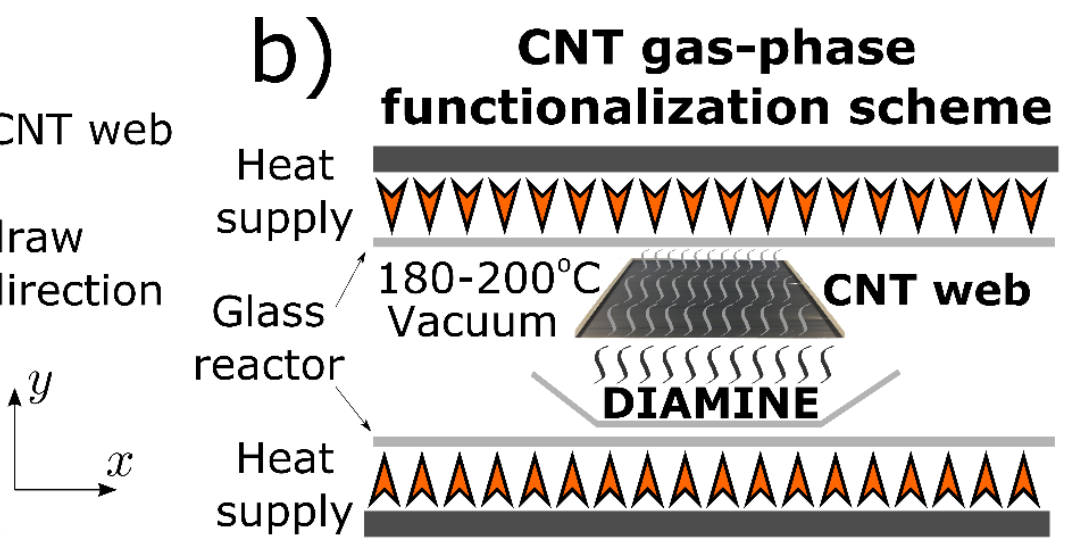

Hierarchical
d)
CNT/CF/Epoxy composite

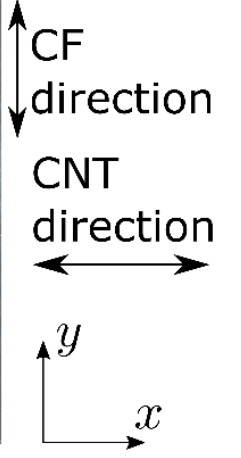

CNT

interleave

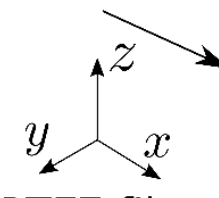

PTFE film

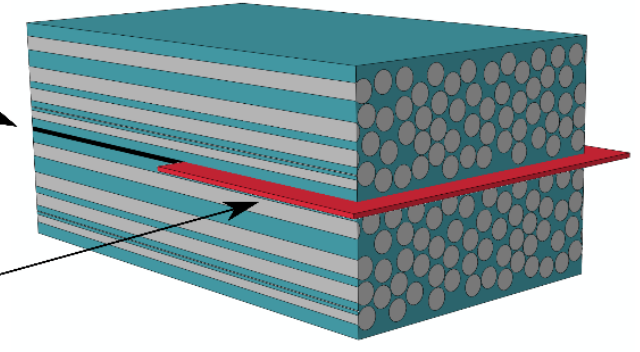

Figure S1. CNTw (10 layers) supported on an aluminium frame (a); CNTw gas-phase amino functionalisation reactor (b); CNTw placed at $90^{\circ}$ with respect of the CF during the preparation of the composite (c) preparation of DCB specimen for Mode I fracture toughness testing $(\mathrm{d})$. 

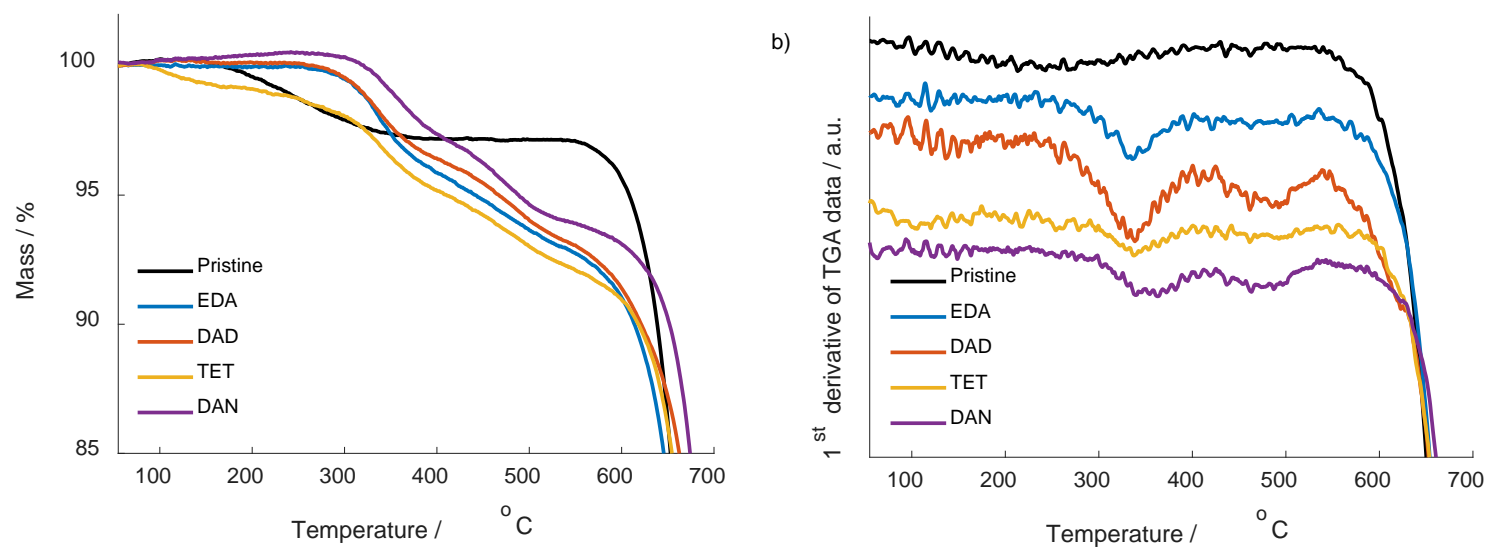

Figure S2. TGA (a) and first derivative (b) of pristine and amino-functionalised CNTw.

The $2 \mathrm{D}$ area of the diamines were calculated using the projected shadow of the more stable 3D conformer given at PubChem open source database (Open Chemistry Database provided by the National Center for Biotechnology Information from the U.S. National Library of Medicine), correlating the total area with the distance of the C-C in an aliphatic chain $(0.154 \mathrm{~nm})$ or in an aromatic structure $(0.137 \mathrm{~nm})$. To make such calculus, all the molecules were oriented flat, that is, oriented in such a way that the projected shadow is maximised.

This allowed to calculate the total area per gram that could be covered with a monolayer of the corresponding amine in such a flat orientation $(M)$ using the following formula:

$$
M=\frac{N}{P}
$$

where $N$ is the calculated area for the corresponding amine times the Avogradro's number, in $\mathrm{m}^{2} \cdot \mathrm{g}^{-1}$ and $P$ is the molecular weight of the corresponding diamine in $\mathrm{g} \cdot \mathrm{mol}^{-1}$. To calculate the CNT surface area $(S)$, an average CNT were selected, with 7 walls, an outer diameter of $10 \mathrm{~nm}$ and an average space between layers of $0.34 \mathrm{~nm}$. Considering the 
CNT as a perfect cylinder, a theoretical graphene surface area of $2600 \mathrm{~m}^{2} \cdot \mathrm{g}^{-1}$, and taking into account only the contribution to the surface of the outermost layer, a CNT specific surface area of $233 \mathrm{~m}^{2} \cdot \mathrm{g}^{-1}$ is obtained. The surface area of the graphene was divided by two, since endohedral interactions were disregarded and thus only one side of the graphene plane was considered to be accessible in the CNT.

The weight loss between $400{ }^{\circ} \mathrm{C}$ and $600{ }^{\circ} \mathrm{C}$ were assigned to a combustion of the outermost layer of the CNT only, and thus the surface of CNT in contact with the diamine was calculated ascribing all the weight lost to the seventh graphene concentric layer of the CNT.

The equivalent amine monolayer (EAM) coverage was obtained dividing the total amount of surface that could be covered by a given monolayer of diamine over the total surface of CNT to be covered, by using the formula:

$$
\operatorname{EAM}(\%)=\frac{\frac{W}{100} M}{\left(1-\frac{W}{100}\right) S} 100
$$

Where $W$ is the corresponding weight \% of amine incorporated, as calculated from the weight loss between $200{ }^{\circ} \mathrm{C}$ and $410{ }^{\circ} \mathrm{C}$; $M$ is the total area per gram that could be covered with a monolayer of the corresponding amine $\left(\mathrm{m}^{2} \cdot \mathrm{g}^{-1}\right)$; and $S$ is the BET surface area of the $\operatorname{CNT}\left(\mathrm{m}^{2} \cdot \mathrm{g}^{-1}\right)$ 

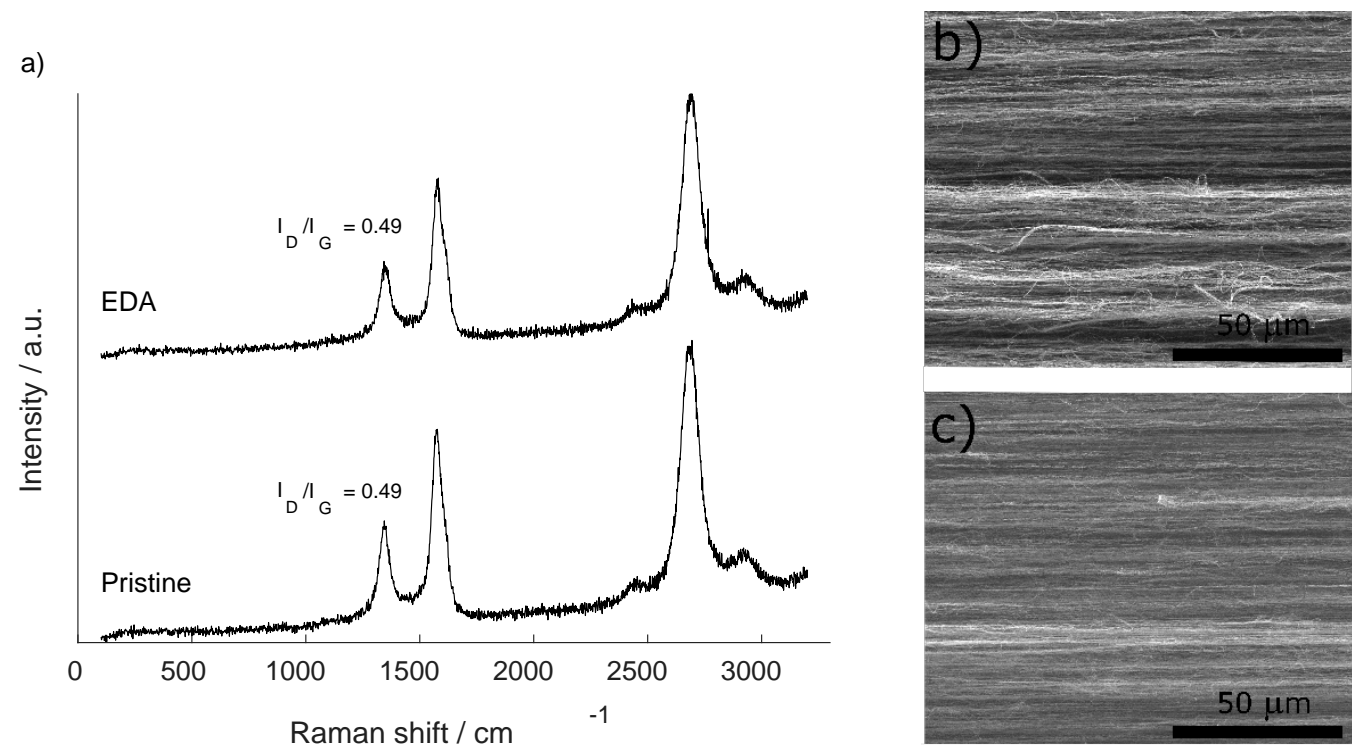

Figure S3. Raman spectroscopy (a) and SEM images of pristine (b) and EDA (c) treated CNTw.
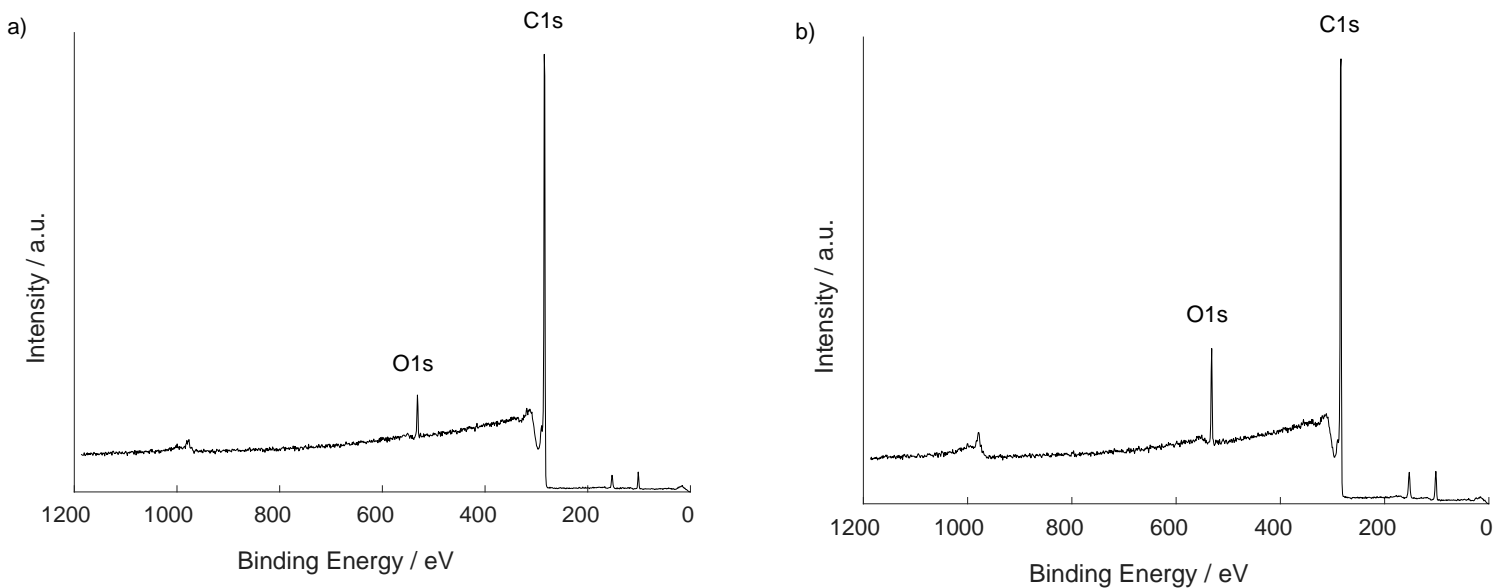

Figure S4. XPS survey of pristine (a) and EDA-functionalised (b) CNTw.

An XPS survey scan was taken for both samples in order to study the overall chemical composition. The binding energies of the photoelectron spectra were referenced to the $\mathrm{sp}^{2}$ component of carbon, at $284.3 \mathrm{eV}$. After a Shirley-type background subtraction, peak 
fitting was performed by using a combination of Doniach-Sunjic and Gaussian-Lorentzian function for the asymmetric component of C1s. For symmetric components, a GaussianLorentzian fitting function was used. Data processing was performed using CasaXPS software.

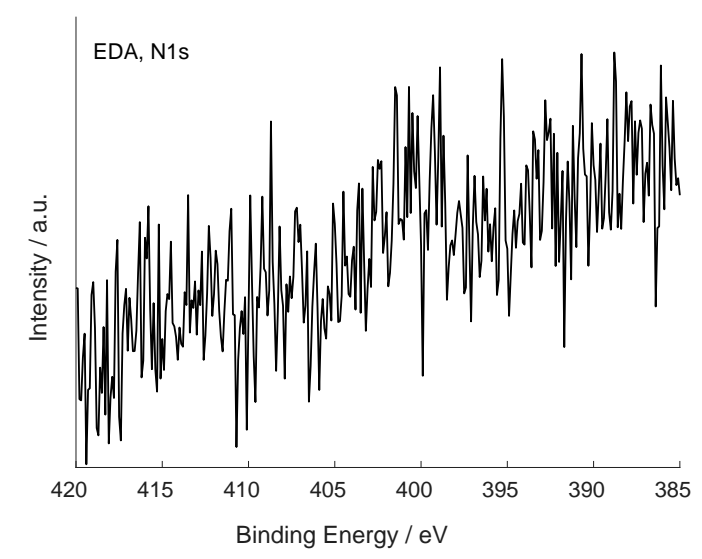

Figure S5. N 1s peak region of EDA treated CNTw. 

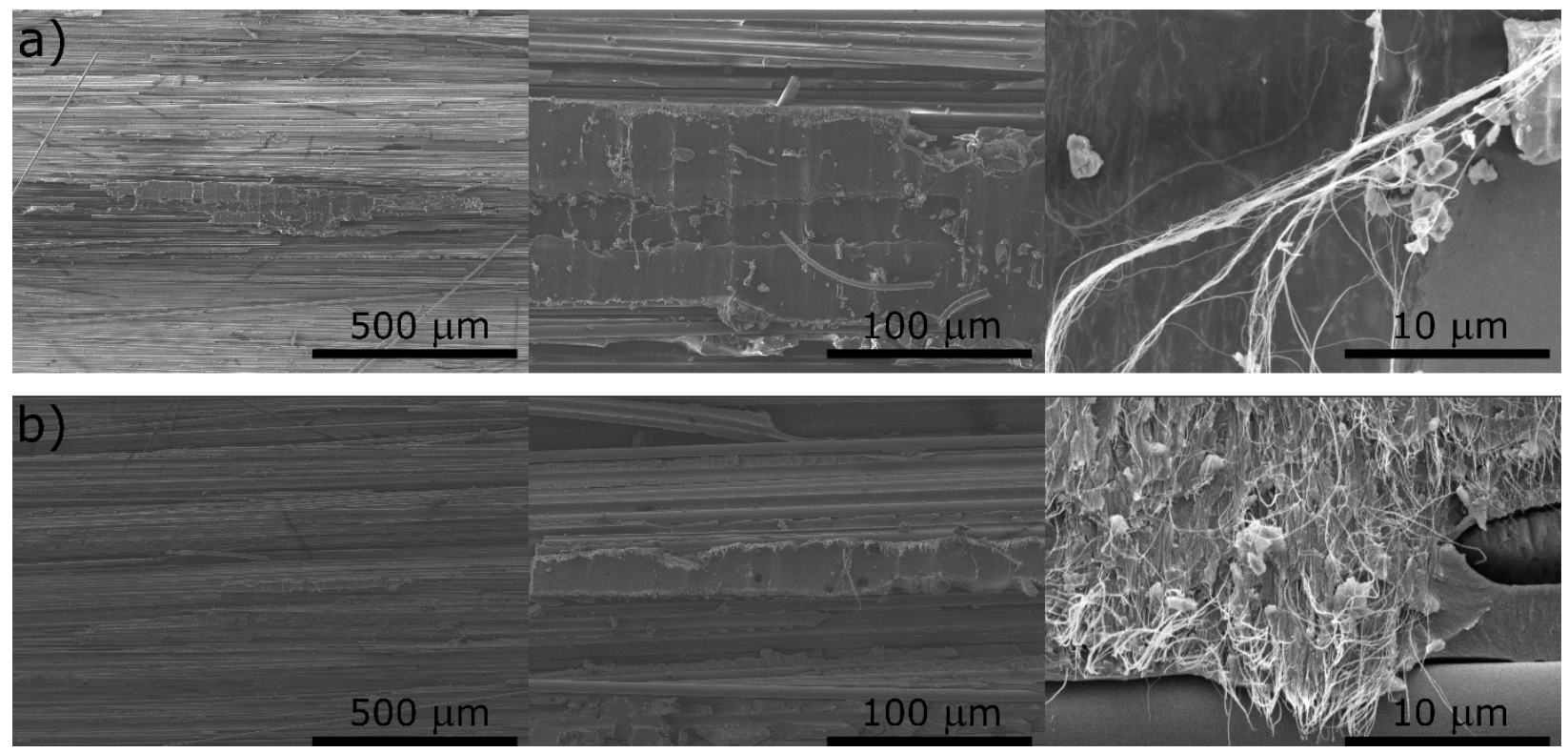

Figure S6. SEM images of the fracture surface of CF/SE84LV reinforced with DAD treated CNTw (a) and TET treated CNTw (b). 